\section{Estratégias de Nomeações Ministeriais: entre a política e as políticas públicas}

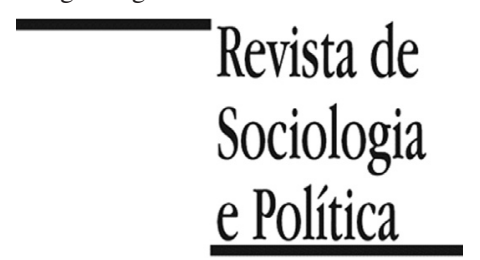

DOI 10.1590/1678987319277001

\author{
Pedro Lucas de Moura Palotti' ib \\ e Pedro Luiz Costa Cavalcante' \\ Instituto de Pesquisa Econômica Aplicada, Brasília, DF, Brasil.
}

RESUMO Introdução: Os ministros são atores políticos centrais na elaboração e implementação de políticas públicas, defesa e representação política de grupos sociais e de interesse, aconselhamento e assessoramento dos chefes de governo, além de exercerem autoridade máxima no campo específico sob sua jurisdição para diversas demandas cotidianas. Nesse contexto, a composição dos gabinetes indica a permeabilidade de aspectos políticos e também de elementos técnicos na condução dos problemas a cargo dos ministérios. Assim, quais os perfis dos ministros recrutados pelos governos eleitos da Nova República, sobretudo, em termos de inserção político-partidária e de expertise técnica? Materiais e Métodos: Para responder essa questão, este artigo propõe a utilização do Índice de Politização Ministerial (IPM) a partir de uma base de dados original dos ministros titulares do governo Collor à interrupção do segundo mandato de Dilma Rousseff (1990 a 2016). Resultados: Como resultado, o trabalho demonstra elevada qualificação do ministro mediano no Brasil democrático, bem como a predominância do perfil que agrega experiências nas arenas política e também técnica. Observam-se também diferenças no padrão de nomeação entre os governos tucanos e petistas. Enquanto os primeiros selecionam mais empresários e especialistas, os governos petistas foram mais politizados e nomearam mais frequentemente empregados, mulheres e negros. Discussão: Em suma, ao agregar na análise dos ministros a perspectiva da trajetória pessoal e a abordagem da composição partidária no contexto do presidencialismo de coalizão, o artigo contribui para qualificar o debate sobre o Executivo e também sobre as diferenças do sistema partidário no Brasil.

PALAVRAS-CHAVE: presidencialismo de coalizão; ministros de Estado; partidos políticos; elites políticas; Brasil.

Recebido em 15 de Setembro de 2017. Revisado em 29 de Maio de 2018. Aceito em 24 de Agosto de 2018.

\section{Introduçãa $0^{1}$}

\author{
1 Agradecemos aos \\ comentários e sugestões dos \\ pareceristas anônimos da \\ Revista de Sociologia e \\ Política.
}

$\mathrm{O}$ s ministros são atores políticos centrais na elaboração e implementação de políticas públicas, defesa e representação política de grupos sociais e de interesse, aconselhamento e assessoramento dos chefes de governo, além de exercerem autoridade máxima no campo específico sob sua jurisdição para diversas demandas cotidianas. Nesse contexto, a composição dos gabinetes indica a permeabilidade de aspectos políticos e também de elementos técnicos na condução dos problemas a cargo dos ministérios.

Alguns esforços da literatura nacional têm se dedicado à compreensão do perfil típico do ministro no Brasil e entre diferentes governos. Em média, os ministros possuem mais de 50 anos de idade, são do sexo masculino e brancos, sendo provenientes dos estados mais populosos e desenvolvidos economicamente (D'Araujo 2014; D'Araujo \& Lameirão 2009; Franz \& Codato 2016; Palotti 2017). D'Araujo e Ribeiro (2018) argumentam que o padrão no presidencialismo de coalizão brasileiro possui certa representatividade de diferentes regiões brasileiras, com ocupantes das pastas ministeriais altamente educados e experientes, embora não necessariamente nos temas abordados por suas pastas ministeriais.

No entanto, em geral, a literatura ainda apresenta algumas questões sem respostas ou que merecem aprofundamento. Dentre elas, um aspecto que chama a atenção é uma suposta dicotomia entre a afiliação ou inserção política e partidária e a expertise técnica dos ministros do Estado. Na maioria das vezes, a 
opinião pública brasileira propaga a ideia de que boa parte das nomeações ministeriais se fundamenta prioritariamente na dimensão política, uma vez que o chefe do Executivo tenderia a satisfazer os partidos da base com vistas a aumentar sua governabilidade. Assim, o Presidente da República supostamente ignoraria ou desconsideraria atributos técnicos na hora de selecionar seus assessores diretos.

Desse modo, quais os perfis dos ministros recrutados pelos governos eleitos da Nova República, sobretudo, em termos de inserção político-partidária e de expertise técnica? Para responder essa questão, esse trabalho explicita as escolhas envolvidas no recrutamento ministerial no Brasil, contrapondo aspectos políticos e técnicos das nomeações que, em geral, são tratados separadamente pela literatura. Assim, é proposto o Índice de Politização Ministerial (IPM) elaborado a partir da reformulação do trabalho anterior de Borges e Coêlho (2015), de modo atraçar um panorama compreensivo sobre as diferentes dimensões das nomeações ministeriais dos governos democráticos inaugurados com a Constituição de 1988.

Vale ressaltar que essa abordagem contribui para qualificar melhor o debate sobre a suposta dicotomia entre as dimensões política e técnica, a partir de um índice (detalhado posteriormente) que mensura de forma objetiva tais questões. Além disso, as análises comparadas entre governos também são importantes, pois contribuem para o avanço do conhecimento empiricamente válido sobre as características do sistema partidário e do funcionamento do Executivo no Brasil pós-democratização.

Após essa introdução, o trabalho possui mais quatro sessões. Na próxima, são discutidos os dilemas da composição dos ministérios a partir do debate teórico sobre presidencialismo de coalizão. Em seguida, o artigo se debruça sobre a base de dados de modo a explorar o perfil dos ministros no Brasil, sob as dimensões partidária, de educação formal e de trajetória profissional. Na sequência o IPM é apresentado e são realizadas contraposições dos ministros escolhidos de acordo com os governos estudados. Por fim, são esboçadas algumas considerações finais, como também a agenda futura de pesquisa.

\section{Gabinete Ministerial no Presidencialismo de Coalizão: uma equação nada trivial}

A montagem de equipes de governo é um dos principais ativos à disposição dos presidentes para produzir decisões legislativas favoráveis e possibilitar o alcance de suas preferências no que tange à agenda de políticas públicas.

A literatura aponta três estratégias recorrentes para escolha dos ministros de Estado. A primeira se refere à necessidade de o presidente construir apoio legislativo. Presidentes podem governar basicamente pela utilização de leis discutidas e aprovadas pelo legislativo ou por meio de suas prerrogativas constitucionais, de forma mais independente e autônoma (Amorim Neto 2006). Sob certas condições - quando o partido do presidente controla um número considerável de cadeiras no parlamento e as preferências partidárias são mais de centro - presidentes utilizam mais frequentemente leis para implementar sua agenda, nomeando ministros com filiação partidária proporcionalmente ao tamanho das bancadas partidárias na Câmara. Porém, quando presidentes possuem poder de decreto e elevado poder de veto, em casos de governos minoritários e independentes, a nomeação de técnicos e amigos leais nos gabinetes é mais frequente, uma vez que dependem menos do apoio de uma maioria no legislativo para governar.

O segundo argumento presente na literatura é o de que a necessidade de compor alianças no legislativo para governar não explicaria isoladamente a composição dos gabinetes. Ministros possuem um papel central no policy- 
making, recebendo a delegação de elevadas responsabilidades para executar ações que interferem nos resultados alcançados e na maneira como o presidente é avaliado pela população. Assim, há uma delegação feita pelo presidente a seus ministros, o que faz com que possíveis riscos de agência possam existir nesse processo. Os riscos são proporcionalmente maiores quanto maior for a divergência de preferências, objetivos e o conjunto de incentivos entre o principal ou patrocinador e seus agentes, bem como quanto maior os custos para fiscalizar e controlar a ação dos ministros (Martínez-Gallardo \& Schleiter 2014). A nomeação de ministros sem filiação partidária poderia contribuir com o objetivo de presidentes para diminuir riscos de agência.

Além dessas duas, uma terceira possibilidade identificada na montagem de ministérios envolve a representatividade das forças políticas e sociais que deram apoio ao governo e não necessariamente estão atreladas às alianças no Congresso nacional e à implementação de políticas públicas (Dowding \& Dumont 2009; D’Araujo 2014). Isto é, aspectos regionais, étnicos e religiosos, grupos de pressão e interesses, movimentos sociais, atributos pessoais/profissionais, bem como da burocracia estatal, também importam nessa complexa equação.

Em síntese, as escolhas na formação do gabinete ministerial normalmente são dominadas por fatores relacionados à proporcionalidade da representação dos partidos no parlamento, à necessidade de controlar o alto escalão no policymaking, como também nomear ministros que ampliem o caráter representativo do governo sob diferentes perspectivas.

Portanto, a seleção e composição do gabinete ministerial envolvem cálculos estratégicos de diferentes naturezas por parte do chefe do governo. Aspectos relacionados à estrutura partidária do presidente ou primeiro-ministro, sua base de apoio político e social, questões regionais, étnicas e religiosas, bem como variáveis relativas às capacidades individuais dos postulantes tornam as escolhas multicausais, dinâmicas e altamente complexas.

A literatura nacional historicamente foca na primeira estratégia em face do arranjo de presidencialismo de coalizão do sistema político brasileiro (Abranches 1988; Figueiredo \& Limongi 1999; Amorim Neto 2007). Observa-se que no caso brasileiro os fatores institucionais centrífugos, que apontaram para maior divisão e controle do poder político, não operaram como impedimento para formação de coalizões relativamente duradouras e eficazes para produção de decisões governamentais, como muitos inicialmente previram ${ }^{2}$.

2 No entanto, como argumenta Batista (2014), apesar de coligados, os espaços reservados aos parceiros da coalizão são distintos e assimétricos. Analisando a produção legislativa e a alocação orçamentária durante os governos FHC e Lula, a autora evidencia que os partidos da coalizão têm baixo protagonismo na produção legislativa, centrada majoritariamente em ministros do partido do presidente, ao passo que na alocação orçamentária as possibilidades de atuação são mais equânimes.

No entanto, se há evidências sólidas a respeito da eficácia do arranjo institucional brasileiro para aprovação da agenda da maioria (Figueiredo \& Limongi 2007; Limongi \& Figueiredo 2009), há também motivos para preocupação com relação às consequências indesejadas e não intencionais desse arranjo para a legitimidade e para a operação satisfatória e previsível das instituições políticas brasileiras (Amorim Neto 2016) ( $^{3}$.

O dilema envolvendo as nomeações ministeriais, portanto, remete à necessidade de se contra por aspectos relacionados às coalizões de governo, largamente explorados pela literatura, a características que remetam ao perfil ministerial mais propriamente voltado à condução de políticas públicas nos ministérios. A partir da proposta inicial feita por Borges e Coêlho (2015), pretende-se observar o comportamento do Índice de Politização Ministerial (IPM) para composição dos governos eleitos após a redemocratização de 1988. 


\section{Entre a Política e a Expertise Técnica: o que é preciso para ser ministro no Brasil?}

${ }^{3}$ Como enfatizam Melo e Pereira (2013), é importante não perder de vista o fato de que a denúncia, apuração e responsabilização nos desvios provenientes do funcionamento do sistema político brasileiro é, por si só, uma vantagem institucional: denota maior atuação dos controles externos horizontais e verticais sobre $o$ desempenho dos atores políticos, fortalecendo a democracia brasileira.
Pretende-se nessa seção dedicar-se à compreensão dos aspectos relacionados à inserção político-partidária e de expertise técnica dos ministros de Estado no Brasil. Essas duas facetas são centrais para a compreensão de como diferentes governos/partidos formaram seus gabinetes com características diversas a partir da necessidade de formar coalizações de governo.

A base de dados utilizada reúne as nomeações ministeriais para o período de 1990 a maio de 2016. A unidade de análise são as nomeações ministeriais, sendo feito um novo registro cada vez que houvesse: i) alteração de governo (diferentes presidentes ou diferentes mandatos de um mesmo presidente); ou ii) o ministro trocasse de ministério. Ao todo, durante esse período, foram recrutados 347 indivíduos, totalizando 520 diferentes nomeações ministeriais. Maiores detalhes sobre a organização da base de dados podem ser verificados no Apêndice.

\section{III.1. Entre correligionários, aliados e sem filiação partidária}

Como discutido anteriormente, durante o período em análise as composições dos ministérios fundamentadas nos partidos da coalizão têm sido frequentes, no entanto, prevalecem composições heterogêneas e dinâmicas nos gabinetes ministeriais. Como forma de abordar esse fenômeno, a Figura 1 mostra como as pastas são distribuídas entre ministros não filiados a partidos políticos, membros do partido do Presidente e de legendas da base de apoio no Congresso Nacional, por cada mandato presidencial.

Claramente, podemos observar diferentes padrões na formação dos gabinetes ministeriais. Ao longo dos governos Collor e Itamar, as parcelas relativas ao partido do Presidente, Partido da Renovação Nacional (PRN), eram insignificantes (2\%), ainda menores do que a proporção da legenda na Câmara Baixa (8\%), eleita em 1990. No entanto, este último, que se tornou presidente após a renúncia de Collor, não estava mais vinculado ao PRN naquele momento e decidiu construir uma coalizão mais ampla com dez principais partidos políticos no Brasil. Essa estratégia tornou seu ministério com divisão praticamente exata entre os membros não filiados e representantes das coalizões.

Desde então, a participação de políticos nos gabinetes ministeriais tem crescido significativamente. No governo Cardoso, nota-se uma leve redução

Figura 1 - Composição dos Ministérios, por mandato (1990-2016)

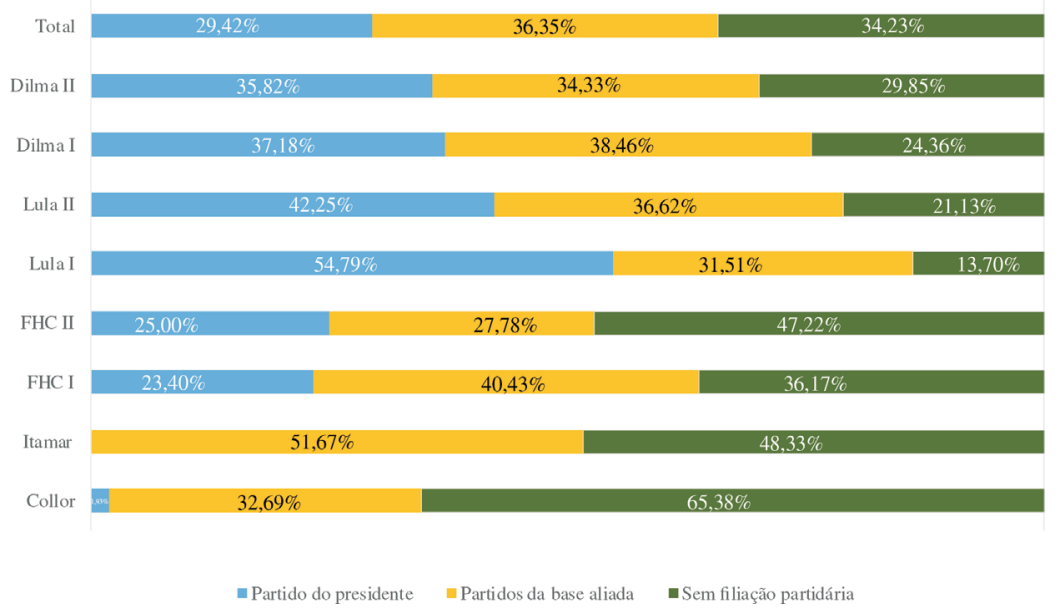

Fonte: Elaboração própria. 
dos ministros não filiados e crescimento na participação dos seus correligionários e sem filiação partidária, principalmente, no segundo mandato. Durante a gestão de FHC, destaca-se o fato de o componente político-partidário do seu ministério ser composto por seis legendas com proximidade ideológica (Power e Zucco Jr., 2009) e que detinham ampla maioria no Congresso Nacional.

A maior representativade dos ministros do mesmo partido do Presidente ocorre no primeiro mandato de Lula quando PT levou mais de metade do gabinete, depois da primeira vitória no Executivo Federal. Esse cenário muda no segundo mandato, de $54 \%$ para $42 \%$, tanto por causa do aumento dos ministros do partido de coalizão quanto devido ao crescimento da parcela não partidária. Embora Lula tenha também conseguido ampla maioria no Congresso durante sua gestão, a configuração da sua coalizão de apoio é bem diferente em relação ao governo FHC, tanto em termos quantitativos, um total de dez partidos, quanto na dimensão ideológica é bem mais heterogênea, incluindo partidos considerados de esquerda como o próprio PT e PCdoB e de direita como o PR e PP (Power e Zucco Jr., 2009).

Finalmente, observamos que o primeiro governo Dilma manteve um padrão de distribuição em alguma medida similar ao do seu predecessor, o que deve ser considerado em face da diversidade de partidos que compunham a base de Dilma Rouseff no primeiro mandato (eram nove legendas). A proporção de ministros do seu partido (PT) continuou acima da média do período $(37,18 \%$ contra 29,42\%), assim como os ministros da coalizão também correspondem a um percentual ligeiramente maior. No entanto, nos dezoito meses do segundo mandato, nota-se uma nítida alteração na composição. A parcela de não filiados no primeiro mandato de Dilma era bem abaixo da média para todo o período analisado (24,36\% em Dilma I contra 39,23\% no período 1990-2016). Na gestão seguinte, o percentual de não filiados passa a se aproximar da média do período estudado, uma vez que representa $29,85 \%$ das nomeações. Surpreendentemente, o padrão de distribuição do gabinete ministerial do segundo governo Dilma é o mais equilibrado em termos percentuais de participação e mais próximo da média do período.

Vale ressaltar que diferente das nações parlamentares que possuem alta representatividade dos congressistas, em regimes presidencialistas os gabinetes são compostos por uma quantidade considerável de ministros não partidários (Amorim Neto e Samuels, 2010; Martínez-Gallardo e Schleiter, 2014). No caso brasileiro, até mesmo a maioria desses ministros partidários não ocupa cargo no

${ }^{4}$ No Brasil, os parlamentares têm direito à licença para ocupar cargos de ministro sem perda do mandato.
Congresso Nacional. Em média, os parlamentares nomeados ministros ${ }^{4}$ representam cerca de um quarto, embora isso varie bastante, por exemplo, $32 \%$ no primeiro mandato de FHC e $18 \%$ no segundo governo Dilma.

\section{III.2. Educação formal e trajetória profissional}

Além da dimensão partidária, aspectos relacionados aos ministros do ponto de vista individual e da trajetória profissional são relevantes para a compreensão das escolhas feitas pelo chefe do Executivo para a composição de seu gabinete ministerial.

A análise dos governos eleitos após a Constituição de 1988 pode ser realizada sob duas óticas: a formação acadêmica e a carreira anterior ao cargo de ministro. Quanto à primeira, assim como em outros países, os gabinetes formados no Brasil possuem integrantes da elite da nação, que geralmente têm elevados níveis de escolaridade (Blondel \& Thiébault 1991; Escobar-Lemmon \& Taylor-Robinson 2009; Pinto \& Almeida 2009). A Tabela 1 mostra que quase $95 \%$ dos ministros nomeados entre 1990 e 2016 possuía ao menos ensino superior, e cerca de $45 \%$ possuía mestrado ou doutorado. A áreas de formação mais 
Tabela 1 - Educação Formal

\begin{tabular}{|c|c|c|c|}
\hline Variável & Categorias & Valor & n $(\%)$ \\
\hline \multirow[t]{5}{*}{ Educação formal } & $\begin{array}{l}\text { Ensino fundamental ou } \\
\text { médio }\end{array}$ & & $33(6,3 \%)$ \\
\hline & Graduação & & $188(36,1 \%)$ \\
\hline & Pós-graduação lato sensu & & $76(14,6 \%)$ \\
\hline & Mestre & & $100(19,2 \%)$ \\
\hline & Doutor & & $123(23,6 \%)$ \\
\hline \multirow{12}{*}{$\begin{array}{l}\text { Tipo de } \\
\text { formação }\end{array}$} & Direito & Sim & $170(34,9 \%)$ \\
\hline & Engenharia & Sim & $74(15,2 \%)$ \\
\hline & Economia & Sim & $104(21,3 \%)$ \\
\hline & $\begin{array}{l}\text { Administração e } \\
\text { contabilidade }\end{array}$ & Sim & $66(13,5 \%)$ \\
\hline & Medicina e saúde pública & Sim & $24(4,9 \%)$ \\
\hline & Ciências sociais e Humanas & Sim & $81(16,6 \%)$ \\
\hline & Formação militar & Sim & $32(6,5 \%)$ \\
\hline & Outros cursos & Sim & $88(18,0 \%)$ \\
\hline & $\begin{array}{l}\text { Número de formações } \\
\text { concluídas }\end{array}$ & 1 & $358(73,5 \%)$ \\
\hline & Média = 1,31 & 2 & $108(22,2 \%)$ \\
\hline & Desvio-padrão $=0,56$ & 3 & $19(3,9 \%)$ \\
\hline & & 4 & $2(0,4 \%)$ \\
\hline \multirow[t]{13}{*}{ Carreiras } & Acadêmico & Sim & $170(32,7 \%)$ \\
\hline & Profissional liberal & Sim & $143(27,5 \%)$ \\
\hline & Servidor público & Sim & $168(32,3 \%)$ \\
\hline & Militar & Sim & $36(6,9 \%)$ \\
\hline & Executivo & Sim & $115(22,1 \%)$ \\
\hline & Empregado rural e urbano & Sim & $87(16,7 \%)$ \\
\hline & Cargo eletivo & Sim & $236(45,4 \%)$ \\
\hline & Outra profissão & Sim & $33(6,3 \%)$ \\
\hline & $\begin{array}{l}\text { Número profissões } \\
\text { exercidas }\end{array}$ & 1 & $202(38,8 \%)$ \\
\hline & Média = 1,9 & 2 & $197(37,8 \%)$ \\
\hline & Desvio-padrão $=0,9$ & 3 & $95(18,2 \%)$ \\
\hline & & 4 & $23(4,4 \%)$ \\
\hline & & 5 & $3(0,5 \%)$ \\
\hline
\end{tabular}

Fonte: Elaboração própria.

${ }^{5}$ Esses dados são basicamente os mesmos encontrados por D’Araujo e Lameirão (2009), apesar das diferenças metodológicas. Neste estudo, houve a inclusão do governo Sarney, não foram incluídos os governos Dilma Rousseff e foram considerados os comuns foram direito (35\%), economia (21\%), ciências sociais e afins (16\%), engenharia (15\%), e administração e contabilidade $(13 \%)^{5}$. Resultado também convergente com o histórico da burocracia brasileira que desde a época do Império era liderada pela notória elite dos letrados, com predominância da carreira jurídica, especialmente formada na Europa (Carvalho 1980).

Aproximadamente um quarto dos ministros nomeados possuía formação em mais de uma área. Segundo D’Araujo e Lameirão (2009 p.111), que analisam separadamente a área de formação por nível de educação, essa formação 
ministros singulares e não as nomeações ministeriais. Além disso, as áreas de formação foram avaliadas nos diferentes níveis - da graduação ao doutorado. No presente trabalho, um mesmo ministro poderia possuir mais de uma formação, avaliada como tal independentemente do nível, e foram seguidas as categorias definidas por

Escobar-Lemmon e

Taylor-Robinson (2009) multidisciplinar ocorre em razão da pós-graduação, em que são incluídos conteúdos mais valorizados para atuação governamental e no mercado, como economia, administração e ciências sociais.

No que tange à profissão anterior à nomeação como ministro, dimensão relevante nos estudos sobre elites políticas (Franz Jr. \& Codato 2016; Vieira, Cardozo \& Pratti 2016), os resultados são semelhantes ao de outros sistemas presidencialistas e de alguns semipresidencialistas, ou até parlamentaristas, com menor predomínio de políticos generalistas (Dowding \& Dumond 2009). Mais de $60 \%$ exerceu mais de uma profissão antes de assumir o cargo de ministro, em sua maioria algum cargo eletivo (45\%), acadêmicos (33\%) servidores públicos (32\%) e profissionais liberais $(27 \%)$.

Escobar-Lemmon e Taylor-Robinson (2009) descobriram, para uma amostra de cinco regimes presidencialistas, que $79 \%$ das indicações ministeriais possuíam formação ou experiência profissional relevante para a pasta em que foram indicados. Para o caso brasileiro, estima-se que $75 \%$ das nomeações ministeriais ocorridas no período estudado tiveram afinidade ou especialização conectada com os ministérios aonde foram alocados. Esse padrão assemelha-se ao identificado em outros regimes presidencialistas, contrastando com o padrão de parte dos regimes parlamentaristas, cujos gabinetes são predominantemente de políticos generalistas, ou seja, sem atributos técnicos ou gerenciais vinculados à pasta em que são alocados.

\section{Uma proposta de síntese entre trajetória política e expertise técnica: comparando governos a partir do Índice de Politização Ministerial}

\footnotetext{
6 Ver o Apêndice para maiores detalhes sobre a composição e validação do IPM.
}

A presente seção apresenta o Índice de Politização Ministerial (IPM), que sintetiza aspectos correlatos do nível de politização das nomeações a partir de variáveis relacionadas à filiação política e à formação educacional e experiência profissional em relação à pasta ministerial ocupada pelos ministros de Estado. Com base em proposta piloto formulada por Borges e Coêlho (2015) para compreensão da politização de nomeações nos ministérios de Ciência, Tecnologia e Inovação e Integração Nacional de 1999 a 2010, foi realizada e testada estatisticamente uma proposta de mensuração da politização das nomeações em todos os ministérios desde a redemocratização ${ }^{6}$.

Essa medida é relevante por atender a duas finalidades: a) sintetizar em um índice aspectos diversos da biografia dessas elites políticas; e b) propiciar uma medida objetiva de politização para análise das estratégias presidenciais de nomeação e substituição de ministros, característica recentemente incorporada em trabalhos sobre a nomeação de cargos discricionários na burocracia (Lewis 2009; Praça, Freitas \& Hoepers 2011). Sua aplicação ao caso brasileiro resultou em um achado interessante: aparentemente não houve um trade-off tão claro entre a politização das nomeações ministeriais, a proporcionalidade da distribuição das pastas ministeriais em relação ao domínio de cadeiras na Câmara dos Deputados pelos partidos políticos ou o caráter majoritário dos gabinetes. Os presidentes manejaram de forma distinta essas três características. Ademais, essa abordagem visa não apenas explorar as características grau de politização e experiência profissional dos ministros, mas também comparar eventuais padrões distintos de seleção dos presidentes e seus partidos, como a literatura nacional já vem indicando (Figueiredo 2007; D’Araujo 2014; Franz Jr. \& Codato 2016).

Para tanto, utilizamos o Índice de Politização Ministerial, composto a partir de ajustes na proposição desenvolvida inicialmente por Borges e Coêlho (2015). Essas variáveis foram mobilizadas a partir das informações públicas sobre cada um dos ministros ${ }^{7}$. A medida compreende variáveis que traduzem 


\footnotetext{
7 A base de dados foi organizada principalmente a partir das biografias reunidas no âmbito do Centro de Pesquisa e Documentação de História Contemporânea do Brasil (CPDOC) da Fundação Getúlio Vargas, com complementações feitas a partir de buscas na internet e nos acervos históricos dos jornais Folha de São Paulo e Estadão. A construção da base está detalhada no Apêndice do artigo.
}

aspectos da atuação política e experiência técnica, numa escala de sete pontos, indo de 0 a 6 , fazendo-se o somatório direto de seis variáveis binárias:

a) Filiação partidária - estar filiado a partido político quando foi nomeado ministro; (Sim - 1 ponto);

b) Cargo eletivo - ter exercido qualquer mandato eletivo (no Executivo ou Legislativo, em qualquer nível governamental) anteriormente à indicação ao cargo de ministro; (Sim - 1 ponto);

c) Cargo na administração partidária - ter ocupado algum cargo na estrutura administrativa do partido político (presidência nacional; presidência estadual ou municipal; secretaria geral; tesouraria etc., inclusive na sua fundação); (Sim - 1 ponto);

d) Formação acadêmica - possuir formação acadêmica em nível de mestrado ou doutorado; (Não - 1 ponto);

e) Servidor público ou militar - ter tido atuação profissional anteriormente como servidor público de carreira ou militar; (Não - 1 ponto);

f) Experiência gerencial na área - ter exercido cargos gerenciais diretamente relacionados ao cargo de ministro ocupado, em âmbito nacional ou subnacional; (Não - 1 ponto).

Na mesma linha seguida por Borges e Coêlho (2015), argumenta-se que o extremo inferior da escala (valores 0 e 1 ) abriga ministros com perfis predominantemente técnico e especializados nas policies gerenciadas nos ministérios, ao passo que o extremo superior reúne os políticos profissionais, ministros com elevada vinculação partidária e atuação política (valores 5 e 6). Os valores intermediários (2, 3 e 4 ) abrigam perfis mistos, "técnico-políticos", com níveis intermediários quanto à inserção política e atuação técnica. A opção por variáveis dicotômicas se deve, principalmente, devido à impossibilidade de acesso a informações mais detalhadas dos currículos, como o tempo de ocupação de cargos na executiva de partidos ou em cargos públicos, em um intervalo temporal tão extenso como o da base dessa pesquisa.

Recorrentemente a ciência política e a opinião pública têm discutido a nomeação dos ministros com ênfase nasua delegação político-partidária. De forma esquemática, trabalha-se com a chave analítica de ministros filiados a partidos políticos em contraposição a experts ou ministros sem filiação partidária. Em adição a esse recorte, uma perspectiva alternativa é a que insere outras dimensões que possam evidenciar diferenças no estágio de carreiras políticas como a contraposição entre políticos seniores e juniores, feita por Inácio (2013) - a formação educacional e a experiência gerencial na área de política pública do ministério, elementos relevantes do background dessas elites políticas.

A distribuição das nomeações ministeriais conforme sua maior ou menor politização pode ser observada na Figura 2. Observa-se valores organizados em uma distribuição bimodal, o que aponta a existência de estratégias variadas de nomeações. Há uma concentração maior nos níveis intermediários (valores de 2 a 4), nos quais se encontra pouco mais de $43 \%$ das nomeações. Em média, durante o período entre 1990 e 2016, o valor do índice de politização foi igual a 3,02 . Isto é, essa evidência empírica contradiz a visão estereotipada, muito propagada pela opinião pública, de que o alto escalão do governo é mal qualificado e/ou indicado tão somente por seus envolvimentos políticos. $\mathrm{Na}$ prática, os resultados demonstram que essas dimensões não necessariamente são excludentes, sobretudo quando parte significativa da amostra orbita nos índices intermediários, logo, são tão políticos quanto técnicos. 
Figura 2 - Distribuição das nomeações ministeriais pelo Índice de Politização Ministerial

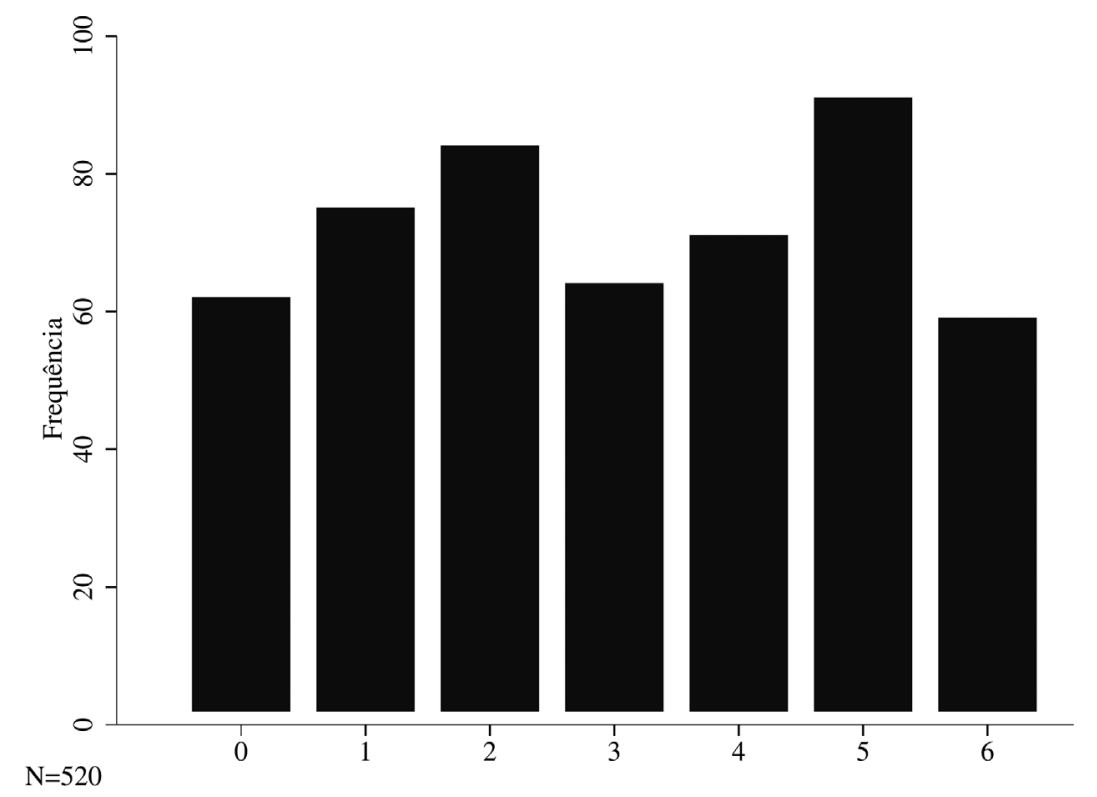

Fonte: Elaboração própria.

Em segundo lugar estão as nomeações mais politizadas (valores 5 e 6), com cerca de $30 \%$. Por fim, mas não muito distante da anterior, estão as nomeações com perfil estritamente técnico (valores 1 e 2), somando aproximadamente $27 \%$ dos casos.

\section{IV.1. Comparação entre governos}

As Figuras 3 e 4 apresentam a distribuição das nomeações ministeriais pelo Índice de Politização Ministerial para os mandatos presidenciais da atual democracia brasileira, em conjunto com a proporcionalidade dessa distribuição em

Figura 3 - Índice de Politização Ministerial médio por mandato presidencial (19902016)

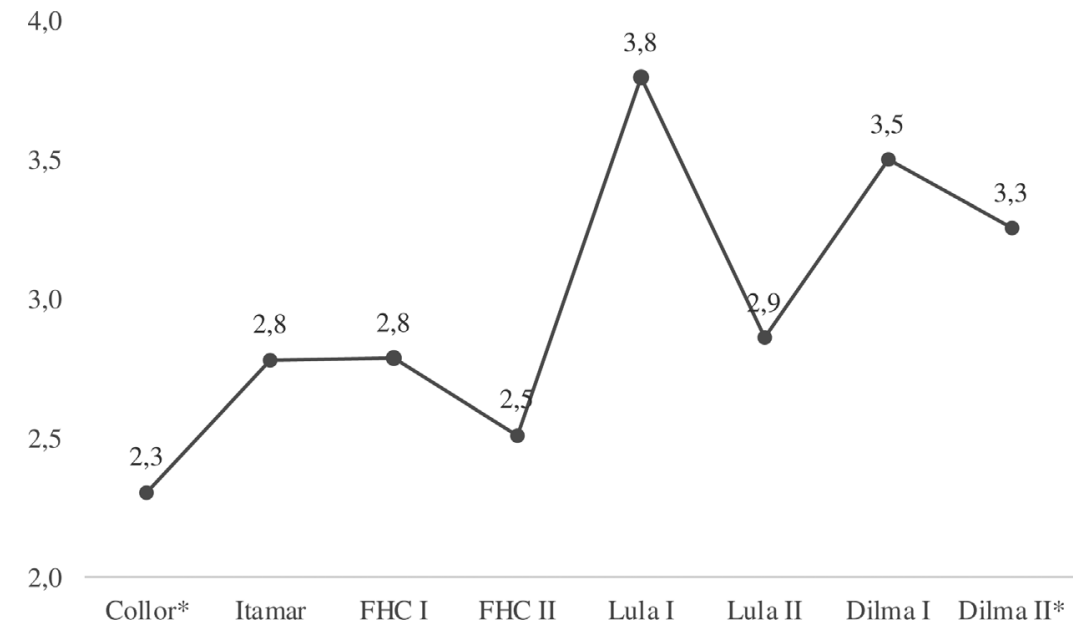

Fonte: Elaboração dos autores.

* O cálculo foi realizado considerando o período que se encerra na data em que os presidentes foram afastados do governo para julgamento do processo de impeachment. 
Figura 4 - Distribuição das nomeações ministeriais pelo Índice de Politização Ministerial para os mandatos presidenciais (1990-2016)

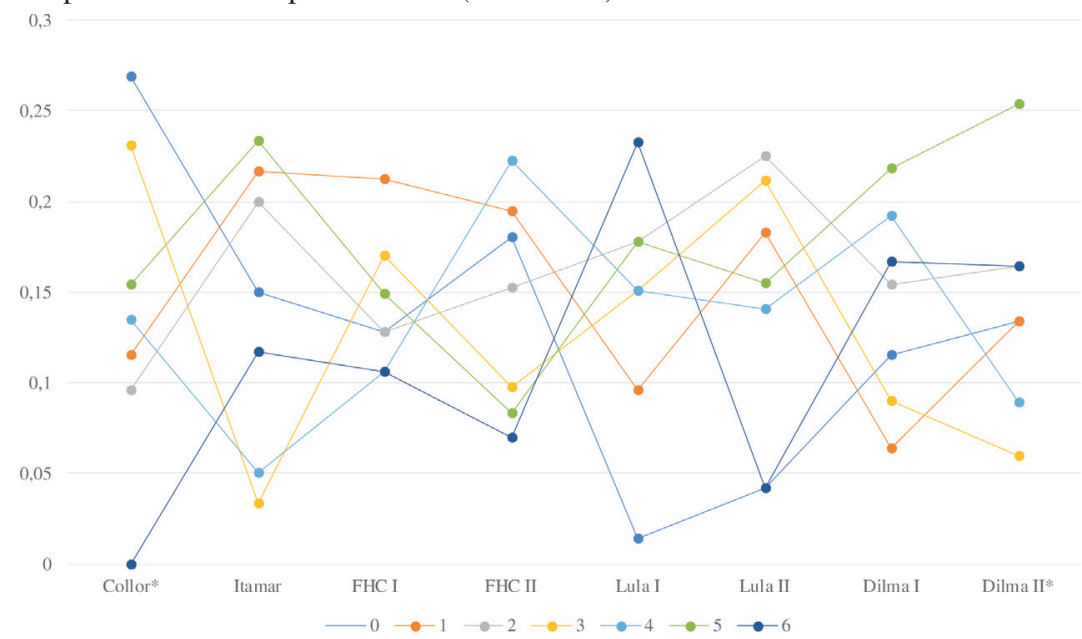

Fonte: Elaboração própria.

* O cálculo foi realizado considerando o período que se encerra na data em que os presidentes foram afastados do governo para julgamento do processo de impeachment.

relação às cadeiras controladas pelos partidos aliados e com os tipos de coalizões realizadas. Algumas diferenças entre os mandatos presidenciais puderam ser apontadas. O governo Collor foi o que indicou o maior percentual de ministros com baixo nível de politização, não tendo realizado nomeações que alcançassem a pontuação máxima (valor 6, na Figura 4). Esse achado se alinha a outros trabalhos que apontam esse governo como marcado pela indicação de outsiders do sistema político brasileiro, distribuindo os ministérios de forma desproporcional (Amorim Neto 2000; Figueiredo 2007).

Não obstante tenha mantido um número significativo de indicados com perfil mais técnico, o mandato de Itamar Franco caracterizou-se pela formação de coalizões majoritárias e mais politizadas que o governo Collor, alcançando também maior proporcionalidade, embora inferior aos mandatos dos presidentes que o sucederam. Figueiredo (2007) adverte que esse governo reuniu um conjunto de políticos experientes de diversos partidos políticos, mesmo daqueles que se mantiveram na oposição, como o Partido dos Trabalhadores (PT) e o Partido Democrático Trabalhista (PDT).

$\mathrm{O}$ primeiro mandato de $\mathrm{FHC}$ apresentou maior equilíbrio entre os distintos tipos de nomeação, assemelhando-se com o retrato geral das nomeações para todo o período observado e alcançando significativo nível de proporcionalidade, de 0,58. Seu segundo mandato ilustra os problemas de coordenação, como a saída do então Partido da Frente Liberal (PFL) da coalizão governamental e a consequente formação de um último gabinete minoritário (Figueiredo 2007). Houve uma diminuição acentuada das nomeações ministeriais com maior nível de politização, ganhando destaque os níveis mais técnicos e intermediários, apesar de a proporcionalidade na distribuição das pastas ter se mantido constante. Em conjunto, os governos liderados pelo Partido da Social Democracia Brasileira (PSDB) possuíram uma politização ministerial inferior à média dos outros governos, embora a proporcionalidade da distribuição de cadeiras na coalizão tenha sido relativamente elevada para o período (Amorim Neto 2000).

O primeiro governo Lula se destaca pelo maior nível de politização de todos os governos no período. Em seu primeiro ano de governo, houve uma elevada distribuição de pastas ministeriais a membros do partido do presidente, e a 
formação de uma coalizão minoritária na qual fizeram parte principalmente os partidos que participaram da coalizão eleitoral. O restante do mandato, entretanto, apresentou em média alta politização e razoável proporcionalidade na distribuição das cadeiras entre os membros da coalizão, que se tornou majoritária com a entrada do Partido do Movimento Democrático Brasileiro (PMDB) no segundo ano de mandato. O segundo governo Lula ampliou a importância dos outros parceiros na coalizão, balanceando a distribuição de pastas, que obteve o maior nível médio para um mandato presidencial $(0,597)$, e optando por diminuir a politização das nomeações. Os dois últimos mandatos de Dilma Rousseff voltam a politizar de forma mais acentuada a escolha dos ministros, principalmente em seu primeiro mandato.

A análise dos mandatos presidenciais no Brasil aponta para a inexistência de um trade-off entre politização e proporcionalidade dos gabinetes. No período, alguns presidentes optaram por dar maior protagonismo ao seu próprio partido na montagem das coalizões, combinando politização e desproporcionalidade. Em outros, níveis menores de politização estiveram associados a coalizões ora mais (como o segundo mandato de FHC), ora menos proporcionais (como o mandato de Collor). $\mathrm{O}$ mesmo parece ocorrer com relação à politização comparada ao caráter mais ou menos majoritário das coalizões. Embora coalizões minoritárias tendam a ser menos politizadas - pelo simples fato de contarem com menos representantes provenientes do Congresso - é possível haver coalizões minoritárias com elevado nível de politização, como ilustra a composição inicial do primeiro governo Lula. Assim, em conjunto com a proporcionalidade e com a composição congressual, o perfil das escolhas e nomeações ministeriais parece variar de modo independente, constituindo-se como uma dimensão adicional da estratégia do chefe do Executivo para a gestão das coalizões governamentais. Esse, sem dúvida, é um achado interessante na medida em que prevalece uma vinculação entre governos minoritários com tecnocratismo na literatura internacional (Dowding \& Dumont 2009).

A Tabela 2 reúne os resultados da aplicação de uma análise de variância (ANOVA) para as médias de três conjuntos de governos durante o período: os governos Itamar/Collor, os governos do PSDB e os governos do PT, sucedida por um teste post-hoc de Fisher-Hayter para a comparação entre pares de governos. Foram contrapostos um conjunto de variáveis para o tipo de nomeação ministerial conforme o perfil das nomeações, começando do Índice de Politização Ministerial, depois as variáveis demográficas, de vinculação política, de formação educacional e, por fim, de trajetória profissional anterior.

Em comparação aos governos do PSDB, os governos de Collor e Itamar Franco não se diferenciaram em relação à politização ministerial, nem quanto às características demográficas dos ministros, com exceção do estado de atuação. $\mathrm{Na}$ Tabela 6, as nomeações de ministros atuantes em São Paulo têm uma probabilidade menor de ocorrer que para os governos tucanos. Os governos Collor e Itamar Franco também se mostraram mais propensos a nomear ministros provenientes de famílias de políticos tradicionais em relação a tucanos e petistas, e menos frequentes na indicação de indivíduos com formação em economia que os governos tucanos. Em conjunto, esses dois presidentes não tenderam a nomear nenhum tipo de profissional com maior ou menor frequência que os gabinetes formados por FHC.

Os governos petistas nomearam em média ministros com maior índice de politização que os governos de Collor e Itamar, e que os tucanos. Como pode ser observada na Tabela 2, essa diferença se manteve estatisticamente significante ao nível de 5\%. Em relação às características demográficas, os governos Lula e Dilma Rousseff nomearam uma proporção superiorde negros ou mulheres aos demais governos. Na dimensão regional, as nomeações de paulistas dos gover- 
Tabela 2 - Testes ANOVA entre os governos Collor/Itamar, do PSDB e do PT

\begin{tabular}{|c|c|c|c|c|c|c|c|c|}
\hline Variáveis & & Collor/Itamar & Gov. do PSDB & Gov. do PT & $\begin{array}{l}\text { Diferença entre } \\
\text { médias para } \\
\text { Collor/Itamar vs. } \\
\text { Gov. do PSDB }\end{array}$ & $\begin{array}{c}\text { Diferença entre } \\
\text { médias para } \\
\text { Collor/Itamar vs. } \\
\text { Gov. do PT }\end{array}$ & $\begin{array}{l}\text { Diferença da média } \\
\text { de Gov. do PSDB vs. } \\
\text { Gov. do PT }\end{array}$ & Estatística ANOVA \\
\hline $\begin{array}{l}\text { Índice de Politização } \\
\text { Ministerial }\end{array}$ & & 2,5625 & 2,6218 & 3,3599 & 0,0593 & $0,7974 * *$ & $0,7380 * *$ & $10,36^{* * *}$ \\
\hline Mulher & & 0,0536 & 0,0252 & 0,1246 & 0,0284 & $0,071 * *$ & $0,0994 * *$ & $6,36^{* * *}$ \\
\hline Negro & & 0 & 0,0168 & 0,1073 & 0,0168 & $0,1073 * *$ & $0,0905^{* *}$ & $11,03 * * *$ \\
\hline Idade & & 53,7946 & 54,563 & 55,6194 & 0,7684 & 1,8247 & 1,0564 & 1,96 \\
\hline São Paulo & & 0,1875 & 0,3445 & 0,2388 & $0,157 * *$ & 0,0513 & $0,1058 * *$ & $4,12 * *$ \\
\hline Família de políticos & & 0,2321 & 0,1261 & 0,1073 & $0,1061 * *$ & $0,1249 * *$ & 0,0188 & $5,46^{* * *}$ \\
\hline Amigo do presidente & & 0,125 & 0,1345 & 0,1488 & 0,0095 & 0,0238 & 0,0143 & 0,21 \\
\hline Clientela ministerial & & 0,1518 & 0,1176 & 0,1557 & 0,0341 & 0,0039 & 0,0381 & 0,51 \\
\hline \multirow[t]{5}{*}{ Formação } & Administração & 0,0561 & 0,1217 & 0,1736 & 0,0657 & $0,1175 * *$ & 0,0518 & $4,67 * * *$ \\
\hline & Direito & 0,37380 & ,4087 & 0,3132 & 0,0349 & 0,0606 & 0,0955 & 1,8 \\
\hline & Engenharia & 0,1121 & 0,1826 & 0,1547 & 0,0705 & 0,0426 & 0,0279 & 1,08 \\
\hline & Economia & 0,1308 & 0,2783 & 0,2189 & $0,1474 * *$ & 0,088 & 0,0594 & $3,67 * *$ \\
\hline & $\begin{array}{l}\text { Sociais e } \\
\text { Relações } \\
\text { Internacionais }\end{array}$ & 0,1682 & 0,1652 & 0,166 & 0,003 & 0,0022 & 0,0008 & 0 \\
\hline \multirow[t]{4}{*}{ Profissão } & Acadêmico & 0,3125 & 0,395 & 0,3045 & 0,0825 & 0,008 & 0,0905 & 1,64 \\
\hline & $\begin{array}{l}\text { Profissional lib- } \\
\text { eral }\end{array}$ & 0,2768 & 0,3025 & 0,263 & 0,0257 & 0,0138 & 0,0395 & 0,33 \\
\hline & Executivo & 0,2946 & 0,3193 & 0,1522 & 0,0247 & $0,1424 * *$ & $0,1671 * *$ & $9,34 * * *$ \\
\hline & $\begin{array}{l}\text { Empregado rural } \\
\text { ou urbano }\end{array}$ & 0,1161 & 0,0756 & 0,2249 & 0,0404 & $0,1088 * *$ & $0,1493 * *$ & $8,30 * * *$ \\
\hline
\end{tabular}

Fonte: Elaboração própria.

Nota: $* \mathrm{p}<0.1 ; * \mathrm{p}<0.05 ; * * * \mathrm{p}<0.01$. ANOVA para comparação entre os três governos. Para a comparação posterior entre pares foi utilizando o teste de Fisher-Hayter. 
nos petistas não se diferenciaram estatisticamente dos governos de Collor/Itamar, os ministros de São Paulo foram mais presentes durante os governos do PSDB.

Para outros formatos de vinculação política, não houve diferenças estatisticamente significativas entre tucanos e petistas. Por fim, os gabinetes formados durante os governos do PT recrutaram com maior frequência ministros com curso superior ou de pós-graduação em administração, ao nível de significância estatística de 5\%, que os governos de Collor e Itamar.

Observou-se, por fim, a presença menor de empresários e maior de empregados, ao nível de significância estatística de 5\%, nos governos petistas em comparação aos governos Collor/Itamar e dos tucanos. Esse achado corrobora a caracterização descritiva sobre a formação de governos liderados pelo PT, que no contexto brasileiro, de presidencialismo de coalizão, construíram gabinetes com elevado número de partidos e ideologicamente heterogêneos. Portanto, que a mudança partidária da presidência com Lula e Dilma refletiu em diferenças basilares entre o PT e o PSDB também na composição dos seus gabinetes ministeriais. Enquanto o primeiro tem características mais próximas de partido de massas, com integrantes de origem externa do sistema político tradicional e recrutamento na base sindical, movimentos sociais e minorias (e.g. negros e mulheres), o segundo se aproxima do conceito de partido de quadros, no qual seus integrantes tendem a fazer parte de grupo social mais homogêneo e elitizado (Duverger 1980).

\section{Considerações Finais}

O presente artigo teve como objetivo principal analisar o perfil dos ministros da Nova República a partir das nomeações para os gabinetes presidenciais no Brasil. Esse mesmo problema de pesquisa já foi alvo de trabalhos anteriores (Figueiredo 2007; Inácio 2013), sem que, no entanto, fosse proposto um índice para se sintetizar a trajetória dessas elites políticas, neste trabalho chamado de Índice de Politização Ministerial (IPM).

As evidências consistentemente apontaram que os governos petistas foram mais politizados que os demais. Em consonância ao encontrado em outros regimes políticos, governos de esquerda como os do PT nomearam mais frequentemente mulheres e negros que os demais governos. Contudo, apesar de agregar um perfil diferente em vários aspectos do gabinete tucano, não houve diferença estatisticamente significativa entre ambos quanto à recorrência de nomeações de ministros provenientes de famílias políticas. Essa diferença foi significativa para os governos Collor e Itamar.

Observou-se ainda que os presidentes petistas recorreram mais frequentemente a ministros com trajetória pregressa de empregados e menos recorrentemente a empregadores que os presidentes tucanos.

Se, por um lado, os resultados das variáveis e das análises apresentam uma visão positiva da qualificação do ministro mediano no Brasil democrático, haja vista que são, em sua maioria, experientes e com boa formação profissional, por outro, do ponto de vista regional e de gênero, prevalecem severas desigualdades.

A pesquisa empreendida pretendeu aplicar uma análise de variância (ANOVA) para abordar questões constantes na literatura especializada. A proposição e provade um novo indicador para mensurar o grau de politização das nomeações dialogam com contribuições anteriores e pode servir a futuras pesquisas que queiram uma síntese biográfica para essas nomeações- com 
todas as vantagens e desvantagens decorrentes da simplificação desses elementos.

Ademais, a pesquisa também demonstra que os perfis se alteram de forma significativa segundo os mandatos presidenciais. De forma geral, observa-se paulatinamente maior recorrência de nomeações para a coalizão governamental, com o intuito de se organizar uma base de apoio no Congresso Nacional para aprovação da agenda governamental. Entre os governos, os mandatos de FHC foram marcados por maior preponderância de perfis com elevada educação formal, principalmente em seu primeiro mandato, e experiência gerencial. Os governos do PT em geral apresentaram maior variação em relação à educação formal, com destaque para o menor desempenho quanto à experiência gerencial, principalmente no primeiro governo Lula. Em relação à experiência político-partidária, os valores são marcadamente maiores para os governos petistas que para os mandatos tucanos. Para o vínculo político a distribuição se altera, com maior proporção de ministros com esse perfil na presidência de Itamar Franco e FHC do que nos governos petistas, o que era de se esperar em razão da existência de políticos provenientes de famílias tradicionais nesses governos.

Em agendas futuras de pesquisa, almeja-se avançar em relação à utilização do índice proposto para se ampliar a compreensão dos dilemas presidenciais para alocação e demissão ou substituição dos ministros de Estado. Se o perfil e o padrão de recrutamento entre os governos foram analisados corretamente, o que dizer a respeito das estratégias presidenciais de escolha das pastas para nomeálos? Haveria diferenças suficientes entre os ministérios que pudessem interferir na maneira como alocá-los entre diferentes perfis de ministros? Em que medida atributos distintos podem interferir no tempo em que os ministros permanecem à frente das pastas em que foram nomeados? Nomeações com níveis mais elevados de politização implicam maior ou menor probabilidade de terminar antes do mandato presidencial? Pretende-se avançar na caracterização, do ponto de vista do chefe do Executivo, das consequências do presidencialismo de coalizão brasileiro sobre o tipo de escolhas feitas na "gestão das coalizões" sob a perspectiva do recrutamento e renovação do gabinete.

Pedro Lucas de Moura Palotti (pedropalotti@gmail.com) é doutor em Ciência Política pela UnB e Especialista em Políticas Públicas e Gestão Governamental no Instituto de Pesquisa Econômica Aplicada - Ipea.

Pedro Luiz Costa Cavalcante (pedrocavalcante@hotmail.com) é doutor em Ciência Política pela UnB e Especialista em Políticas Públicas e Gestão Governamental no Instituto de Pesquisa Econômica Aplicada - Ipea.

\section{Referências}

Abranches, S., 1988. Presidencialismo de Coalizão: O Dilema Institucional Brasileiro. Dados, vol. 31(1), pp. 5-34.

Amorim Neto, O., 2000. Gabinetes presidenciais, ciclos eleitorais e disciplina legislativa no Brasil. Dados, vol. 43(3), pp.479-519. DOI: 10.1590/S0011-52582000000300003

Amorim Neto, O., 2006. The presidential calculus executive policy making and cabinet formation in the Americas. Comparative Political Studies, vol. 39(4), pp.415-440. DOI: 10.1177/0010414005282381

Amorim Neto, O., 2007. O Poder Executivo, centro de gravidade do Sistema Político Brasileiro. In L. Avelar \& A. O. Cintra. (orgs). Sistema Político Brasileiro: Uma Introdução. 2ed. Revista e Ampliada. Rio de Janeiro: Fundação Konrad Adenauer, pp.131-141.

Amorim Neto, O., 2016. A Crise Política Brasileira de 2015-2016: Diagnóstico, Sequelas e Profilaxia. Relações Internacionais (Lisboa), vol. 52, pp.43-54.

Amorim Neto, O. \& Samuels, D., 2010. Democratic Regimes and Cabinet Politics: A Global Perspective. Revista IberoAmericana de Estudos Legislativos, vol.1 (1), pp.10-23. DOI: 10.12660/riel.v1.n1.2010.4123

Blondel, J. \& Thiébault, J. L., 1991. The Profession of Government Ministers in Western Europe. New York: St. Martins Press.

Borges, A. \& Coêlho, D., 2015. O Preenchimento de Cargos da Burocracia Pública Federal no Presidencialismo de Coalizão Brasileiro: análise comparativa de dois ministérios - ciência e tecnologia e integração nacional. In F. G. Lopez. Cargos de confiança no presidencialismo de coalizão brasileiro. Brasília: IPEA, pp.71-105. 
Carvalho, J. M. de, 1980. A Construção da Ordem. Brasília: Editora Universidade de Brasília.

Cavalcante, P. \& Palotti, P. L. M., 2015. What does it take to remain in office? Ministers profile and duration in a newly established democracy. In 73rd annual MPSA Conference. Chicago.

D’Araujo, M. C., 2014. Elites burocráticas, dirigentes públicos e política no Poder Executivo. In M. C. D’Araujo (org). Redemocratização e mudança social no Brasil. Rio de Janeiro: Editora da FGV, vol. 1, pp.205-229.

D’Araujo, M. C. \& Lameirão, C., 2009. A elite dirigente do governo Lula. Rio de Janeiro: Centro de Pesquisa e Documentação de História Contemporânea do Brasil (CPDOC), Fundação Getúlio Vargas (FGV).

D’Araujo, M. C. \& Ribeiro, G., 2018. Trajetória socioeducacional dos ministros brasileiros na Nova República (1985-2014). Revista de Sociologia e Política, vol. 26, (65), pp.39-61. DOI: 10.1590/1678-987317266503

Dowding, K. \& Dumont, P., 2009. Structural and strategic factors affecting the hiring and firing of ministers. In K. Dowding; P. Dumont, (eds) The selection of ministers in Europe: hiring and firing. Routledge advances in European politics; 52. London: Routledge - Taylor \& Francis Group, pp.1-20.

Duverger, M., 1980. Os Partidos Políticos. Rio de Janeiro: Zahar/UnB.

Escobar-Lemmon, M. \& Taylor-Robinson, M. M., 2009. Do Cabinet Ministers in Presidential Systems have Experience in their Portfolio or is On-the-Job Training the Norm?. International Political Science Association Meeting, Santiago, Chile.

Figuereido, A., 2007. Coalition Government in the Brazilian Democracy. Brazilian Political Science Review, vol. 1 (2), pp.182-216.

Figueiredo, A. \& Limongi, F., 2007. Instituições políticas e governabilidade: desempenho do governo e apoio legislativo na democracia brasileira. In C. Ranulfo Melo, M. A. Sáez (orgs). A democracia brasileira: balanço e perspectivas para o século21, Belo Horizonte: Humanitas, Editora da UFMG, pp.147-198.

Franz Jr., P. \& Codato, A., 2016. O recrutamento ministerial no Brasil: trajetória profissional e filiação partidária de FHC a Lula. In VII Seminário Nacional Sociologia \& Política. Curitiba.

Hair, Joseph F.; Anderson, R.; Tatham, R. \& Black, William C., 2005. Análise Multivariada de Dados. 5a edição. Porto Alegre: Bookman.

Inácio, M., 2013. Escogiendo Ministros y Formando Políticos: los partidos en gabinetes multipartidistas. América Latina Hoy, vol. 64, pp.41-66.

Lewis, D. E., 2009. Revisiting the Administrative Presidency: Policy, Patronage, and Agency Competence. Presidential Studies Quarterly,vol.39 (1), pp.60-73. DOI: 10.1111/j.1741-5705.2008.03658.x

Limongi, F. \& Figueiredo, A., 1999. Executivo e Legislativo na Nova Ordem Constitucional. Rio de Janeiro: Fundação Getúlio Vargas, v. 1.

Limongi, F. \& Figueiredo, A., 2009. Poder de Agenda e Políticas Substantivas. In M. Inacio \& L. Renno (orgs). Legislativo Brasileiro em Perspectiva Comparada. Belo Horizonte: UFMG, pp.77-104.

Lira, S. A. \& Chaves Neto, A., 2005. Pontos de dicotomização para a obtenção do coeficiente de correlação tetracórico. Revista Ciências Exatas e Naturais, vol. 7 (2), pp.195-208.

Martínez-Gallardo, C. \& Schleiter, P., 2014. Choosing Whom to Trust: Agency Risks and Cabinet Partisanship in Presidential Democracies. Comparative Political Studies, vol. 48, (2), pp.231-264. DOI: 10.1177/0010414014544361

Mauerberg JR., A., 2016. Cabinet composition and assessment of a multiparty presidential system. Tese de Doutorado. São Paulo: Escola de Administração de Empresas de São Paulo da Fundação Getúlio Vargas.

Palotti, P., 2017. Estratégias de seleção e substituição de ministros de Estado no presidencialismo de coalizão brasileiro: perfil, alocação e rotatividade. Tese de Doutorado. Brasília: Universidade de Brasília.

Pinto, A. C. \& Almeida, P. T., 2009. Portugal: the primacy of 'independents'. InK. Dowding \& P. Dumont, (orgs).The selection of ministers in Europe: hiring and firing. Routledge advances in European politics; 52. London: Routledge - Taylor \& Francis Group, pp.147-158.

Power, T. \& Zucco Jr., C., 2009. Estimating Ideology of Brazilian Legislative Parties, 1990-2005: A Research Communication. Latin American Research Review, Baltimore, vol. 44 (1), pp.218-246. DOI: 10.1353/lar.0.0072

Praça, S.; Freitas, A. \& Hoepers, B., 2011. Political Appointments and Coalition Management in Brazil, 2007-2010. Journal of Politics in Latin America,vol. 3, (2) pp.141-172. DOI: 10.1177/1866802x1100300205

Vieira, S. M.; Cardozo, H. A. B. \& Pratti, L. P., 2016. Trajetória política dos ministros e distribuição partidária nos gabinetes ministeriais no Brasil. 10 Encontro da Associação Brasileira de Ciência Política (ABCP). Belo Horizonte. 
Ministerial Appointments Strategies: between policy and public policy

ABSTRACT Introduction: Ministers are crucial stakeholders in the policymaking, advocacy and political representation of social and interest groups, advising and support the chief of government, and exercising maximum authority in the specific field under their jurisdiction for several daily demands. In this context, the composition of the cabinets indicates the permeability of political aspects as well as technical elements in handling of the policy issues by the ministries. So what are the profiles of ministers appointed by elected governments in Brazil, especially in terms of party political affiliation and technical expertise? Materials and Methods: To answer this question, this article proposes the Ministerial Politization Index (IPM) from an original database of the Collor government ministers to the interruption of Dilma Rousseff's second term (1990 to 2016). Results: As a result, the paper shows a high qualification of the median minister in democratic Brazil, as well as predominance of the profile that assemble experiences in the political and technical arenas. There are also differences in the appointment patterns between PSDB and PT administrations. While the former select more entrepreneurs and specialists, PT has been more politicized and more often appointed employees, women and blacks. Discussion: In sum, by adding in the ministers' analysis both the personal trajectory perspective and the party composition approach in the context of coalition presidentialism, the article contributes to qualify the debate about the Executive and also regarding the party system differences in Brazil.

KEYWORDS: coalition presidentialism; ministers of State; political parties; political elites; Brazil.

This is an Open Access article distributed under the terms of the Creative Commons Attribution Non-Commercial License which permits unrestricted non-commercial use, distribution, and reproduction in any medium provided the original work is properly cited. 


\section{Apêndice}

\section{A1. Construção da base de dados}

\footnotetext{
8 A única consideração de interinato é aquela em que ministros anteriormente interinos são nomeados como titulares na mesma pasta. Nesses casos, o tempo como interino foi incluído como tempo total de permanência à frente da pasta.

${ }^{9}$ Uma versão anterior da base de dados havia sido criada no segundo semestre de 2014, tendo sido utilizada por Cavalcante e Palotti (2015). Por não incluir alguns campos específicos, além de todo o segundo governo Dilma Rousseff, foi deixada à parte como referência para esclarecer divergências entre as duas bases anteriores.
}

As nomeações ministeriais foram compiladas durante os meses de julho e agosto de 2016. Apesar de a maioria dos dados se referirem a informações biográficas constantes no acervo do Centro de Pesquisa e Documentação de História Contemporânea do Brasil (CPDOC) da Fundação Getúlio Vargas, estas foram complementadas por outras fontes quando necessário, principalmente partir dos acervos digitais dos jornais Estado de São Paulo e Folha de São Paulo, da Wikipedia e de buscas na internet. Para facilitar o registro e a recuperação da informação, foi criada uma ficha biográfica para cada indivíduo pesquisado, independentemente do número de nomeações que tenha recebido, com os links e textos utilizados, bem como a fotografia dos ministros, fonte para o preenchimento da variável raça/cor.

As referências sobre as nomeações ministeriais foram retiradas diretamente do site oficial da Presidência da República, desconsiderando-se as indicações de interinos ${ }^{8}$. Foi realizada a triangulação para conferência dos dados coletados. Duas versões distintas da base de dados ${ }^{9}$ foram criadas de forma independente por dois assistentes de pesquisa, sendo posteriormente contrapostas entre si. As incongruências foram resolvidas caso a caso, com o registro dessas escolhas em cada ficha biográfica. Para diminuir a ocorrência de erros, a filiação partidária e as datas de posse e exoneração dos ministros foram conferidas com os anexos presentes no trabalho de Mauerberg Jr. (2016).

A organização da base de dados é semelhante à realizada por Franz Jr. e Codato (2016) e por Vieira, Cardozo e Pratti (2016). Um mesmo indivíduo é repetido a cada nomeação ministerial, tenha ela ocorrido em outro ministério ou no mesmo ministério em distintos mandatos presidenciais. Assim, por exemplo, Guido Mantega aparece em quatro linhas diferentes na base de dados, como ministro do Planejamento, durante o início do primeiro governo Lula, e três vezes como ministro da Fazenda, no final do primeiro governo Lula e nos dois mandatos seguintes, de Lula e Dilma Rousseff. Já Adib Jatene aparece duas vezes como ministro da Saúde, a primeira durante o governo Collor e a segunda no primeiro mandato de Fernando Henrique Cardoso. Apesar de ter ocupado a mesma pasta, o fez em mandatos presidenciais distintos.

A disposição dos registros no banco de dados por mandatos presidenciais difere da existente em outros trabalhos, como os de Escobar-Lemmon e Taylor-Robinson (2009). Em ambos, os ministros foram considerados como uma mesma observação se se mantiveram a frente da mesma pasta ao longo de diferentes governos ou se migraram para outros postos. Essa abordagem tem como vantagem a verificação de qualidades e atributos que possam manter o mesmo indivíduo ao longo do tempo no gabinete. Já Inácio (2013) adota como ponto de partida a ocupação à frente das pastas ministeriais, considerando trocas ministeriais, mas não os diferentes governos.

No presente trabalho, argumenta-se que há efeitos não desprezíveis da substituição de ministros sobre a condução de uma pasta ao longo de um mesmo mandato presidencial, ainda que este seja mantido no gabinete. Esse fato, em conjunto com o objetivo de se avaliar o perfil, as estratégias de nomeação e de substituição considerando-se os mandatos presidenciais tornou mais adequadaa nomeação ministerial como unidade de análise considerando as diferentes pastas e governos. . 


\section{A2. Índice de Politização Ministerial (IPM)}

A proposta do IPM é um desdobramento do índice de partidarização ministerial apresentado por Borges e Coêlho (2015). Sua escala possui sete pontos, indo de 0 a 6 , fazendo-se o somatório direto de seis variáveis binárias.

a) Filiação partidária - estar filiado a partido político quando foi nomeado ministro; (Sim - 1 ponto)

b) Cargo eletivo - ter exercido qualquer mandato eletivo (no Executivo ou Legislativo, em qualquer nível governamental) anteriormente à indicação ao cargo de ministro; (Sim - 1 ponto)

c) Cargo na administração partidária - ter ocupado algum cargo na estrutura administrativa do partido político (presidência nacional; presidência estadual ou municipal; secretaria geral; tesouraria etc., inclusive na sua fundação); (Sim - 1 ponto)

d) Formação acadêmica - possuir formação acadêmica em nível de mestrado ou doutorado; (Não - 1 ponto)

e) Servidor público ou militar - ter tido atuação profissional anteriormente como servidor público de carreira ou militar; (Não - 1 ponto)

f) Experiência gerencial na área - ter exercido cargos gerenciais diretamente relacionados ao cargo de ministro ocupado, em âmbito nacional ou subnacional; (Não - 1 ponto)

Em comparação à proposta feita por Borges e Coêlho (2015), o presente índice considera como vinculação partidária também a participação do ministro na fundação dos partidos, para a variável "cargo na administração partidária”, e a formação em nível de pós-graduação stricto sensu ao invés de pós-graduação lato sensu como demarcador de perfis mais ou menos técnicos. Em relação às profissões anteriormente assumidas pelos ministros, os militares também foram considerados como perfis especializados em assuntos governamentais, ao lado dos servidores públicos de carreira ${ }^{10}$.

\section{A3. Testes estatísticos do Índice de Politização Ministerial}

\footnotetext{
10 Além disso, Borges e Coêlho (2015) construíram um índice com 9 pontos na escala, variando de 0 a 8 , graças à aplicação de um peso para as variáveis de "filiação partidária" e "cargo eletivo", ambas valendo dois pontos. Optou-se por não atribuir pesos pela dificuldade em justificá-los teoricamente. Em todo caso, os resultados dos testes estatísticos de validação dessa variável foram realizados com e sem o uso de pesos, com resultados muito semelhantes entre si.
}

Com o intuito de se confirmar a possibilidade de construção desse índice, procedeu-se inicialmente à verificação de se essas variáveis representam uma dimensão subjacente comum ou uma variável latente. Para tanto, foi utilizada uma análise fatorial exploratória, a partir de uma matriz de correlação tetracórica. A correlação tetracórica é uma técnica desenvolvida para mensurar a existência de variáveis latentes para variáveis binárias, tomadas em par. Assim,

A estimativa obtida com o Coeficiente de Correlação Tetracórico pode ser considerada como uma estimativa do Coeficiente de Correlação Linear de Pearson considerando as variáveis latentes $X_{L}$ e $Y_{L}$ (ambas contínuas e normais), subjacentes às variáveis dicotômicas $\mathrm{X}$ e $\mathrm{Y}$ efetivamente observadas com a dicotomização (Lira \& Chaves Neto 2005 p196).

A Tabela 1A detalha a matriz de correlação das variáveis binárias selecionadas. Observa-se uma forte correlação entre as variáveis de atuação políticopartidária entre si (superior a 0,80 ) e uma associação menor entre o inverso das variáveis que registram atributos técnicos (entre 0,45 e 0,55).

A aplicação da análise fatorial exploratória aponta a identificação de uma única variável latente para esse conjunto de seis variáveis binárias. A Tabela 2A e a Tabela 3A apresentam evidências nesse sentido, seguindo-se as recomendações feitas por Hair Jr. et al. (2005). É recomendável que os fatores possuam eigenvalues superiores a um e que juntos correspondam a pelo menos $60 \%$ da 
11 A análise de correspondência múltipla para essas variáveis também confirma a existência de uma única dimensão. Do total de inércia observada no modelo $(0,13), 93,21 \%$ correspondem à dimensão com essas seis variáveis $(0,12)$. variância explicada. Além disso, espera-se que a carga dos fatores individualmente seja de pelo menos 0,50. Essas especificações são atendidas pelo Fator 1, cujo eigenvalue é 3,696, em termos cumulativos atinge $61,61 \%$ da variância total com fatores acima de 0,60.

Outra referência comumente utilizada é a visualização do screeplot, que apenas reproduz a distribuição de eigenvalues da Tabela 2A. Aplicando-se o critério anteriormente utilizado em relação aos eigenvalues, observa-se na Figura 1A um único fator acima de um. Não se pode observar, contudo, uma estabilização dessa curva, deixando indeterminado o número de fatores. Entretanto, do ponto de vista teórico (Borges \& Coêlho 2015), e a partir dos outros critérios anteriormente apresentados, argumenta-se haver a possibilidade de dimensionar em uma única escala o nível de politização das nomeações ministeriais.

A análise de confiabilidade, por fim, confirma essa escolha, indicando um Alpha de Cronbach de 0,749, acima do parâmetro de 0,70 considerado como limiar mínimo para apontar a existência de unidimensionalidade no fator observado (Hair Jr. et al., 2005) ${ }^{11}$.

Figura 1A - Screeplot

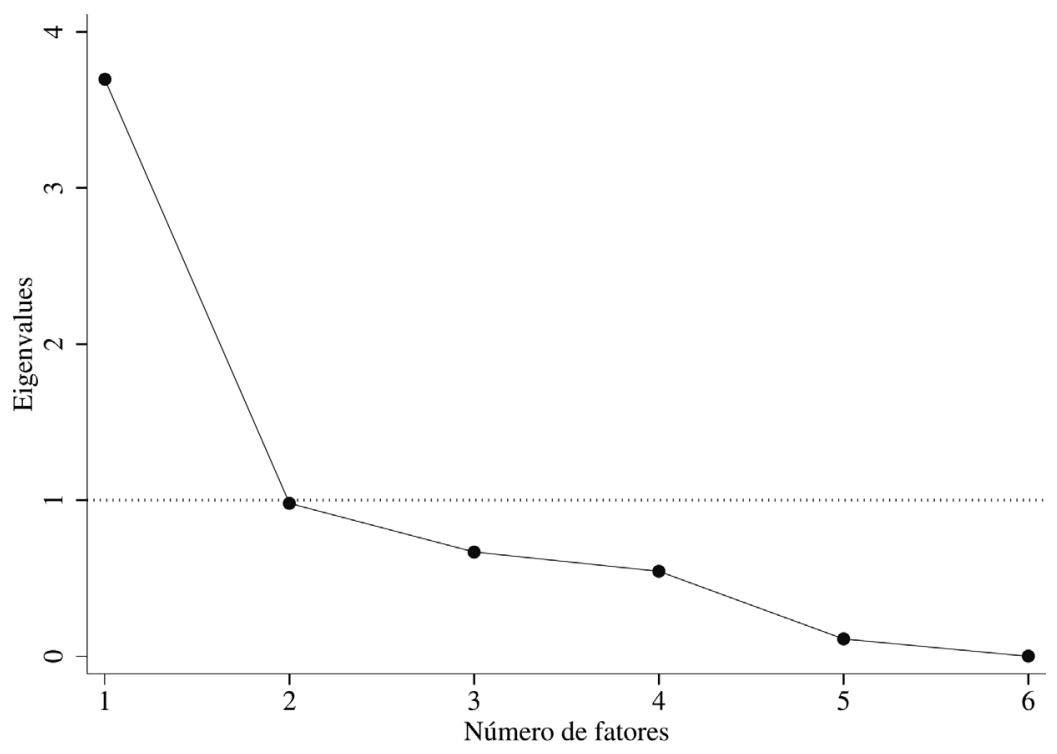

Fonte: Elaboração própria.

Tabela 1A - Matriz de correlações tetracóricas

\begin{tabular}{|c|c|c|c|c|c|c|}
\hline Categoria & $\begin{array}{c}\text { Ocupou } \\
\text { cargo eletivo }\end{array}$ & $\begin{array}{c}\text { Filiação } \\
\text { partidária }\end{array}$ & $\begin{array}{c}\text { Cargo na } \\
\text { administraçã } \\
\text { o partidária }\end{array}$ & $\begin{array}{l}\text { Formação } \\
\text { acadêmica }\end{array}$ & $\begin{array}{l}\text { Servidor } \\
\text { público ou } \\
\text { militar }\end{array}$ & $\begin{array}{l}\text { Experiência } \\
\text { gerencial na } \\
\text { área }\end{array}$ \\
\hline Ocupou cargo eletivo & 1 & & & & & \\
\hline Filiação partidária & 0,88 & 1 & & & & \\
\hline $\begin{array}{l}\text { Cargo na administração } \\
\text { partidária }\end{array}$ & 0,85 & 0,98 & 1 & & & \\
\hline Formação acadêmica & 0,55 & 0,41 & 0,27 & 1 & & \\
\hline Servidor público ou militar & 0,48 & 0,45 & 0,46 & 0,36 & 1 & \\
\hline Experiência gerencial na área & 0,51 & 0,33 & 0,38 & 0,40 & 0,44 & 1 \\
\hline
\end{tabular}

Fonte: Elaboração própria. 
Tabela 2A - Análise fatorial pelo método de fatores principais sem rotação

\begin{tabular}{lcccc}
\hline Fator & Eigenvalues & Diferença & Proporção & Cumulativo \\
\hline Fator1 & 3,69 & 2,71 & 0,61 & 0,61 \\
Fator2 & 0,97 & 0,31 & 0,16 & 0,78 \\
Fator3 & 0,66 & 0,12 & 0,11 & 0,89 \\
Fator4 & 0,54 & 0,43 & 0,09 & 0,98 \\
Fator5 & 0,11 & 0,11 & 0,01 & 1 \\
Fator6 & 0 & $\cdot$ & 0 & 1 \\
\hline
\end{tabular}

Fonte: Elaboração própria.

Nota: LR Teste: independente vs. saturado: $\operatorname{chi} 2(15)=2.0 \mathrm{e}+04$ Prob $>\operatorname{chi} 2=0.0000$

Tabela3A - Carga dos fatores e exclusividade da variância

\begin{tabular}{lcc}
\hline Variável & Fator1 & Exclusividade \\
\hline Ocupou cargo eletivo & 0,94 & 0,11 \\
Filiação partidária & 0,91 & 0,16 \\
Cargo na administração partidária & 0,89 & 0,20 \\
Formação acadêmica & 0,60 & 0,63 \\
Servidor público ou militar & 0,66 & 0,56 \\
Experiência gerencial na área & 0,61 & 0,62 \\
\hline
\end{tabular}

Fonte: Elaboração própria. 